\title{
MENENTUKAN HARGA OPSI DENGAN METODE MONTE CARLO BERSYARAT MENGGUNAKAN BARISAN KUASI ACAK FAURE
}

\author{
Putu Widya Astuti ${ }^{1 \S}$, Komang Dharmawan ${ }^{2}$, Kartika Sari ${ }^{3}$ \\ ${ }^{1}$ Program Studi Matematika, Fakultas MIPA - Universitas Udayana [Email: widy aastuti2452@ gmail.com] \\ ${ }^{2}$ Program Studi Matematika, Fakultas MIPA - Universitas Udayana [Email: k.dharmawan @ unud.ac.id] \\ ${ }^{3}$ Program Studi Matematika, Fakultas MIPA - Universitas Udayana [Email: sarikaartika @unud.ac.id] \\ ${ }^{\S}$ Corresponding Author
}

\begin{abstract}
An option contract is a contract that gives the owner the right to sell or even to buy an asset at the predetermined price and period time. The conditional Monte Carlo is one of the several methods that is used to determine the option price which in the process uses random numbers with normal standard distribution. At the same time, the random number generator can be substituted by using a quasirandom sequence, as in Faure's quasi-random sequence. The aim of this study is to determine the contract price of the call option with the European type by applying the conditional Monte Carlo method. This method used the Faure quasi-random sequence and compared it with the method of Monte Carlo standard, Monte Carlo standard in using the quasi-random sequence of Faure, and conditional Monte Carlo. The results of this study showed that the call option calculated using the conditional Monte Carlo method using the quasi-random Faure sequence began to stabilize at the 5000th simulation for $K=32575$ and $K=34725$ and in the 10000th simulation for $K=33000$ and $K=33950$. Research also show that with the conditional Monte Carlo in using the quasi-random sequence of Faure is more stable. Therefore, it is obtained its real value faster than the Monte Carlo standard, Monte Carlo standard in using the quasi-random sequence of Faure, and conditional Monte Carlo. The MAPE value of conditional Monte Carlo in using the quasi-random sequences of Faure and the Monte Carlo standard is smaller than the Monte Carlo standard in using the quasi-random sequence of Faure, and conditional Monte Carlo. Therefore, it can be said to be more accurate when calculating the European type call option price at BBCA.JK stocks.
\end{abstract}

Keywords: Option Contract, Standard Monte Carlo, Conditional Monte Carlo, Faure quasi-random sequences

\section{PENDAHULUAN}

Kontrak opsi adalah suatu kontrak yang memberikan hak kepada pemiliknya untuk menjual ataupun membeli suatu aset pada harga dan periode waktu yang telah ditentukan. Pada saat menentukan harga opsi dapat dilakukan dengan menggunakan beberapa metode yaitu, metode Black-Scholes, Monte Carlo standar dan Monte Carlo bersyarat. Metode Black-Scholes digunakan untuk menghitung harga opsi Eropa dan digunakan pada opsi yang tidak memberikan deviden. Harga opsi yang diperoleh dengan menggunakan model ini adalah harga yang fair.

Seiring dengan perkembangan zaman, metode yang digunakan dalam menentukan harga opsi juga semakin berkembang. Monte Carlo merupakan algoritma komputasi yang menjalankan percobaan dalam jumlah banyak, yang disebut simulasi, pada data suatu sampel dengan menggunakan variabel acak untuk mendapatkan hasil yang sangat mendekati nilai riilnya. Metode ini memanfaatkan strong law of large number, yang berarti semakin banyak simulasi yang digunakan maka semakin baik pula pendekatan pada nilai riilnya (Zhang, 2009).

Monte Carlo bersyarat adalah bagian dari Monte Carlo Variance Reduction, dimana metode ini memanfaatkan teknik pengurangan varians. Varians dari suatu data dapat berkurang melalui transformasi suatu peubah dengan menggunakan nilai harapan bersyarat. Granovsky (1981) menyebutkan bahwa Conditional Monte Carlo disusun untuk mengestimasi suatu ekspektasi bersyarat dari suatu fungsi, dengan mengambil suatu sampel dari distribusi tidak bersyarat. Penelitian dengan 
menggunakan Monte Carlo bersyarat sebelumnya dilakukan oleh Wati et al. (2018), dimana untuk mengetahui kekonvergenan hasil perhitungan harga opsi call tipe barrier yang dibandingkan dengan metode Antithetic Variate. Artanadi et al., (2017) pernah menggunakan Monte Carlo Control Variate dalam menentukan harga opsibeli tipe Asia.

Pada saat membangkitkan bilangan acak, dapat digantikan dengan menggunakan barisan kuasi acak yaitu barisan kuasi acak Van der Corput, Halton, Sobol, dan Faure. Barisan kuasi acak Faure merupakan barisan dengan dimensi$d$ yang memerlukan koordinat minimum dalam menentukan suatu titik di dalamnya, yang koordinat-koordinat tersebut menggunakan basis yang umum (common base) (Glasserman, 2004). Basis- $b$ terdiri dari bilangan prima terkecil $b \geq 2$ atau setidaknya sama dengan dimensinya sendiri $b \geq d$. Penelitian dengan menggunakan barisan kuasi acak Faure sebelumnya dilakukan oleh Ratnasari et al. (2017), yaitu untuk menentukan nilai kontrak opsi tipe binary pada komuditas kakao menggunakan metode Quasi Monte Carlo. Selain itu Mahayoga et al. (2014) pernah menggunakan barisan kuasi acak Halton pada saat menentukan harga opsi tipe Eropa menggunakan metode Quasi Monte Carlo.

Harga opsi yang diperoleh dengan menggunakan Monte Carlo standar dan Monte Carlo bersyarat menggunakan barisan kuasi acak Faure akan dilihat tingkat keakuratan hasil simulasinya mengggunakan metode Mean Absolute Percentage Error (MAPE). Adapun tujuan dari penelitian ini adalah untuk menentukan harga opsi tipe Eropa dengan Monte Carlo bersyarat menggunakan barisan kuasi acak Faure dan melihat perbandingan hasil perhitungan harga opsi beli tipe Eropa.

\section{METODE PENELITIAN}

\section{Jenis dan Sumber Data}

Data yang digunakan dalam penelitian ini adalah data sekunder yang berupa data kuantitatif, yaitu data historis harga penutupan saham PT Bank Central Asia Tbk. (BBCA.JK). Data diakses melalui https://finance.yahoo.com/ dari tanggal 1 Januari 2017 hingga 1 Januari 2020.

\section{Metode Penelitian}

Pada saat menentukan harga opsi beli tipe Eropa dengan Monte Carlo bersyarat menggunakan barisan kuasi acak Faure menerapkan beberapa langkah. Pertama mengumpulkan data historis harga penutupan saham BBCA.JK. Selanjutnya menentukan tingkat pengembalian (return) dan menentukan volatilitas saham. Kemudian menentukan nilai dari harga saham awal $\left(S_{t_{0}}\right)$, volatilitas saham $(\sigma)$, suku bunga bebas risiko $(r)$, tanggal jatuh tempo $(T)$, dan menentukan harga pelaksanaan $(K)$. Setelah itu menghitung harga opsi beli tipe Eropa dengan metode Black-Scholes menggunakan persamaan

$$
C_{u}=S_{t} N\left(d_{1}\right)-K e^{-r T} N\left(d_{2}\right)
$$

Selanjutnya menghitung harga opsi beli tipe Eropa dengan metode Monte Carlo standar dan Monte Carlo standar mengunakan barisan kuasi acak Faure dengan langkah-langkah:

a. Membangkitkan bilangan acak yang digunakan.

b. Menghitung nilai estimasi dari harga saham dalam periode yang sudah ditentukan menggunakan persamaan

$$
S_{t}=S_{t_{0}} e^{\left(r-\frac{\sigma^{2}}{2}\right) \Delta t+\sigma Z \sqrt{\Delta t}}
$$

c. Menghitung harga opsi beli tipe Eropa sebanyak $\mathrm{N}$ simulasi menggunakan persamaan

$$
C_{u}=e^{-r T} \operatorname{maks}\left(S_{t}-K, 0\right)
$$

d. Menghitung rata-rata dari harga opsi sehingga diperoleh harga opsi beli tipe Eropa.

$$
C_{u}=e^{-r T} \frac{1}{N} \sum_{i=1}^{N} \operatorname{maks}\left(S_{t}-K, 0\right)
$$

Kemudian menghitung harga opsi beli tipe Eropa dengan metode Monte Carlo bersyarat dan Monte Carlo bersyarat menggunakan barisan bilangan kuasi acak Faure, dengan langkah-langkah:

a. Membangkitkan bilangan acak yang digunakan

b. Menghitung nilai estimasi dari harga saham dalam periode yang sudah ditentukan menggunakan persamaan (2).

c. Menghitung harga opsi beli tipe Eropa menggunakan persamaan

$$
E\left(E\left(J_{c} \mid \boldsymbol{Z}\right)\right)=E\left(C_{u}\right)
$$

dimana $C_{u}$ diperoleh dari persamaan (1).

d. Ulangi langkah (a) sampai (c) sebanyak 100, 250, 500, 750, 1000, 5000, 10000, $50000, \quad 100000, \quad 500000,1000000$ simulasi.

e. Menghitung rata-rata dari harga opsi sehingga diperoleh harga opsi beli tipe Eropa. 
Terakhir membandingkan hasil perhitungan harga opsi beli tipe Eropa yang diperoleh. Dalam penelitian ini data diolah menggunakan bantuan software Microsoft Excel 2013 dan MATLAB R2017a.

\section{HASIL DAN PEMBAHASAN}

\section{Data Penelitian}

Data yang digunakan dalam penelitian ini adalah data sekunder yang berupa data kuantitatif, yaitu data historis harga penutupan saham PT Bank Central Asia Tbk. (BBCA.JK), dari tanggal 1 Januari 2017 hingga 1 Januari 2020.

\section{Menentukan Nilai Return dan Volatilitas Saham}

Diawali dengan menentukan nilai return yang akan digunakan untuk menghitung nilai expected return, dengan bantuan Microsoft Excel 2013 diperoleh nilai expected return dari saham BBCA.JK sebesar 0.011806. Nilai return dan expected return yang diperoleh, digunakan untuk menghitung varians dimana untuk menentukan volatilitas, dengan bantuan Microsoft Excel 2013 diperoleh volatilitas saham BBCA.JK sebesar 0.188891194.

\section{Menentukan Faktor-faktor yang Memengaruhi Harga Opsi}

Faktor-faktor yang dapat memengaruhi harga opsi yaitu harga saham aw al $\left(S_{t_{0}}\right)$ dimana menggunakan harga penutupan saham BBCA.JK pada tanggal 30 Desember 2019 sebesar Rp.33.425. Harga pelaksanaan $(K)$ menggunakan harga sebesar Rp.32.575, Rp.33.000, Rp.33.950 , dan Rp.34.725 . Tanggal jatuh tempo $(T)$ dari kontrak opsi adalah setelah enam bulan yaitu tanggal 1 Juli 2020. Volatilitas saham $(\sigma)$ diperoleh berdasarkan perhitungan yang dilakukan sebelumnya yaitu 0.188891194 . Suku bunga bebas risiko $(r)$ diasumsikan konstan sebesar
6,5\% per tahun yang merupakan suku bunga dari Bank Indonesia.

\section{Menghitung Harga Opsi}

Harga opsi yang akan dihitung pada penelitian ini adalah harga opsi beli tipe Eropa. Pertama-tama harga opsi akan dihitung dengan menggunakan metode Black-Scholes, dengan menggunakan bantuan software MATLAB R2017a diperoleh harga opsi beli tipe Eropa secara rinci pada Tabel 1.1.

Tabel 1.1 Harga Opsi Beli tipe Eropa yang

Dihitung dengan Metode Black-Scholes

\begin{tabular}{|c|c|}
\hline & Opsi Beli tipe Eropa (Rp) \\
\hline$K=32575$ & $2.836,861$ \\
\hline$K=33000$ & $2.579,418$ \\
\hline$K=33950$ & $2.059,241$ \\
\hline$K=34725$ & $1.691,590$ \\
\hline
\end{tabular}

Sumber: Data diolah (2020)

Berdasarkan Tabel 1.1 dengan menggunakan metode Black-Scholes diperoleh bahwa semakin besar nilai $K$ maka harga opsi yang diperoleh akan semakin kecil.

Selanjutnya menghitung harga opsi dengan metode Monte Carlo standar, Monte Carlo standar menggunakan barisan kuasi acak Faure, Monte Carlo bersyarat dan Monte Carlo bersyarat menggunakan barisan kuasi acak Faure, dengan simulasi yang digunakan adalah 100, 250, 500, 750, 1000, 5000, 10000, 50000, 100000, 500000, 1000000. Pada metode Monte Carlo standar dan Monte Carlo bersyarat diaw ali dengan membangkitan bilangan acak berdistribusi normal standar. Sedangkan pada Monte Carlo standar dan bersyarat menggunakan barisan kuasi acak Faure bilangan acak yang dibangkitkan adalah barisan kuasi acak Faure dengan $b=2$ dan $d=2$, dengan bantuan software MATLAB R2017a diperoleh harga opsi beli tipe Eropa yang secara rinci disajikan pada Tabel 1.2, 1.3, 1.4, dan 1.5. 
Tabel 1.2 Harga Opsi Beli Tipe Eropa yang Dihitung dengan Metode Monte Carlo Standar

\begin{tabular}{|c|c|c|c|c|}
\hline \multirow{2}{*}{$\begin{array}{c}\text { Jumlah Simulasi } \\
(\mathrm{N})\end{array}$} & \multicolumn{4}{|c|}{ Harga Opsi Beli tipe Eropa (Rp) } \\
\cline { 2 - 5 } & $K=32575$ & $K=33000$ & $K=33950$ & $K=34725$ \\
\hline 100 & $2.767,658$ & $2.506,316$ & $2.035,613$ & $1.678,977$ \\
\hline 250 & $2.834,832$ & $2.460,537$ & $2.072,030$ & $1.712,530$ \\
\hline 500 & $2.867,779$ & $2.618,016$ & $1.998,220$ & $1.635,131$ \\
\hline 750 & $2.832,211$ & $2.571,988$ & $2.072,990$ & $1.672,762$ \\
\hline 1000 & $2.826,275$ & $2.547,883$ & $2.060,113$ & $1.723,812$ \\
\hline 5000 & $2.841,506$ & $2.569,392$ & $2.073,115$ & $1.678,320$ \\
\hline 10000 & $2.857,916$ & $2.573,155$ & $2.065,735$ & $1.691,7484$ \\
\hline 50000 & $2.833,943$ & $2.580,200$ & $2.056,585$ & $1.695,191$ \\
\hline 100000 & $2.837,434$ & $2.579,518$ & $2.057,843$ & $1.687,099$ \\
\hline 500000 & $2.833,480$ & $2.580,380$ & $2.061,323$ & $1.690,441$ \\
\hline 1000000 & $2.835,722$ & $2.578,420$ & $2.058,511$ & $1.692,094$ \\
\hline
\end{tabular}

Sumber: Data diolah (2020)

Tabel 1.3 Harga Opsi Beli Tipe Eropa yang Dihitung dengan Metode Monte Carlo Standar Menggunakan Barisan Kuasi Acak Faure.

\begin{tabular}{|c|c|c|c|c|}
\hline \multirow{2}{*}{$\begin{array}{c}\text { Jumlah Simulasi } \\
(\mathrm{N})\end{array}$} & \multicolumn{4}{|c|}{ Harga Opsi Beli tipe Eropa (Rp) } \\
\cline { 2 - 5 } & $K=32575$ & $K=33000$ & $K=33950$ & $K=34725$ \\
\hline 100 & $2.937,550$ & $2.719,503$ & $2.267,261$ & $1.946,800$ \\
\hline 250 & $3.102,470$ & $2.874,760$ & $2.426,779$ & $2.105,061$ \\
\hline 500 & $3.119,877$ & $2.894,771$ & $2.443,363$ & $2.119,673$ \\
\hline 750 & $3.152,265$ & $2.927,425$ & $2.472,399$ & $2.146,132$ \\
\hline 1000 & $3.161,324$ & $2.937,851$ & $2.481,997$ & $2.153,691$ \\
\hline 5000 & $3.184,448$ & $2.961,762$ & $2.504,959$ & $2.173,736$ \\
\hline 10000 & $3.191,854$ & $2.969,555$ & $2.511,986$ & $2.179,407$ \\
\hline 50000 & $3.195,195$ & $2.972,633$ & $2.515,351$ & $2.182,467$ \\
\hline 100000 & $3.195,508$ & $2.972,948$ & $2.515,677$ & $2.182,803$ \\
\hline 500000 & $3.195,986$ & $2.973,412$ & $2.516,087$ & $2.183,165$ \\
\hline 1000000 & $3.196,050$ & $2.973,480$ & $2.516,151$ & $2.183,232$ \\
\hline
\end{tabular}

Sumber: Data diolah (2021)

Tabel 1.4 Harga Opsi Beli Tipe Eropa yang Dihitung dengan Metode Monte Carlo Bersyarat

\begin{tabular}{|c|c|c|c|c|}
\hline \multirow{2}{*}{$\begin{array}{c}\text { Jumlah Simulasi } \\
(\mathrm{N})\end{array}$} & \multicolumn{4}{|c|}{ Harga Opsi Beli tipe Eropa (Rp) } \\
\cline { 2 - 5 } & $K=32575$ & $K=33000$ & $K=33950$ & $K=34725$ \\
\hline 100 & $2.800,616$ & $2.640,643$ & $2.029,181$ & $1.702,231$ \\
\hline 250 & $2.894,242$ & $2.643,571$ & $2.067,345$ & $1.731,570$ \\
\hline 500 & $2.928,671$ & $2.635,772$ & $2.160,899$ & $1.831,219$ \\
\hline 750 & $2.954,515$ & $2.624,367$ & $2.095,023$ & $1.738,180$ \\
\hline 1000 & $2.881,642$ & $2.657,183$ & $2.113,583$ & $1.787,548$ \\
\hline 5000 & $2.947,634$ & $2.683,208$ & $2.143,860$ & $1.736,681$ \\
\hline 10000 & $2.933,085$ & $2.683,174$ & $2.120,559$ & $1.757,010$ \\
\hline 50000 & $2.930,874$ & $2.669,262$ & $2.133,921$ & $1.749,489$ \\
\hline 100000 & $2.936,489$ & $2.664,406$ & $2.127,388$ & $1.744,498$ \\
\hline 500000 & $2.928,192$ & $2.662,393$ & $2.125,676$ & $1.746,584$ \\
\hline 1000000 & $2.928,685$ & $2.662,633$ & $2.125,710$ & $1.746,866$ \\
\hline
\end{tabular}

Sumber: Data diolah (2021) 
Tabel 1.5 Harga Opsi Beli Tipe Eropa yang Dihitung dengan Metode Monte Carlo Bersyarat Menggunakan Barisan Kuasi Acak Faure

\begin{tabular}{|c|c|c|c|c|}
\hline \multirow{2}{*}{$\begin{array}{c}\text { Jumlah Simulasi } \\
(\mathrm{N})\end{array}$} & \multicolumn{4}{|c|}{ Harga Opsi Beli tipe Eropa (Rp) } \\
\cline { 2 - 5 } & $K=32575$ & $K=33000$ & $K=33950$ & $K=34725$ \\
\hline 100 & $2.839,334$ & $2.273,350$ & $1.842,110$ & $1.695,544$ \\
\hline 250 & $2.847,242$ & $2.280,891$ & $1.859,849$ & $1.691,609$ \\
\hline 500 & $2.824,495$ & $2.295,483$ & $1.854,252$ & $1.696,372$ \\
\hline 750 & $2.821,450$ & $2.295,575$ & $1.844,095$ & $1.698,993$ \\
\hline 1000 & $2.821,432$ & $2.287,940$ & $1.840,657$ & $1.699,755$ \\
\hline 5000 & $2.817,552$ & $2.298,333$ & $1.830,342$ & $1.701,968$ \\
\hline 10000 & $2.818,166$ & $2.294,716$ & $1.831,457$ & $1.701,752$ \\
\hline 50000 & $2.818,259$ & $2.294,659$ & $1.831,544$ & $1.701,233$ \\
\hline 100000 & $2.818,277$ & $2.294,652$ & $1.831,407$ & $1.701,365$ \\
\hline 500000 & $2.818,168$ & $2.294,299$ & $1.831,454$ & $1.701,259$ \\
\hline 1000000 & $2.818,124$ & $2.294,295$ & $1.831,418$ & $1.701,240$ \\
\hline
\end{tabular}

Sumber: Data diolah (2020)

Berdasarkan Tabel 1.2, 1.3, 1.4, dan 1.5 diperoleh bahwa semakin besar nilai $K$ maka harga opsi semakin kecil. Pada Tabel 1.2 dapat dilihat bahwa harga opsi beli yang diperoleh belum terlihat stabil hingga simulasi ke1000000 , dalam artian harga opsi beli yang diperoleh masih berfluktuatif dikarenakan pembangkitan bilangan acak yang digunakan berdistribusi normal standar sehingga menyebabkan harga opsi beli yang dihitung belum stabil sampai simulasi ke-1000000.

Pada Tabel 1.3 diperoleh bahwa harga opsi beli mulai stabil saat simulasi ke-50000 untuk masing-masing $\mathrm{K}$, hal ini dikarenakan pembangkitan bilangan acak yang dilakukan menggunakan barisan kuasi acak Faure, dimana bilangan acaknya berupa pasangan terurut yang diperoleh berdasarkan dimensi dan basis yang digunakan saat pembangkitan bilangan acak terjadi, sehingga bilangan acaknya tidak berubah-ubah saat dilakukannya simulasi.

Pada Tabel 1.4 dapat dilihat bahwa harga opsi beli untuk masing-masing $\mathrm{K}$ baru mulai stabil saat simulasi ke-500000, dikarenakan Monte Carlo bersyarat memanfaatkan teknik pengurangan varians dimana varians dapat berkurang melalui transformasi suatu peubah dengan menggunakan nilai harapan bersyarat, sehingga dapat mengurangi pengacakan sebanyak mungkin saat simulasi dilakukan. Dengan demikian varians yang diperoleh lebih kecil dan efisiensi kinerja dari metode Monte Carlo meningkat.
Dari Tabel 1.5 diperoleh bahwa harga opsi beli mulai stabil pada saat simulasi ke-5000 saat $K=32575$ dan $K=34725$ dan pada saat simulasi ke- 10000 saat $K=33000$ dan $K=$ 33950. Hal ini dikarenakan metode Monte Carlo bersyarat memanfaatkan teknik pengurangan varians, dimana varians dapat berkurang melalui transformasi suatu peubah dengan menggunakan nilai harapan bersyarat, sehingga dapat mengurangi pengacakan yang terjadi saat dilakukannya simulasi dengan demikian varians yang diperoleh lebih kecil dan efisiensi dari kinerja metode Monte Carlo meningkat. Tidak hanya itu pembangkitan bilangan acak menggunakan barisan kuasi acak Faure, dimana bilangan acaknya berupa pasangan terurut yang diperoleh berdasarkan dimensi dan basis yang digunakan saat pembangkitan bilangan acak terjadi, sehingga bilangan acaknya tidak berubah-ubah saat dilakukannya simulasi. Hal inilah yang menjadikan metode Monte Carlo bersyarat menggunakan barisan kuasi acak Faure lebih cepat stabil.

\section{Menghitung Nilai MAPE}

Tingkat keakuratan dari hasil simulasi yang dilakukan dapat dihitung menggunakan beberapa metode, salah satunya ialah MAPE (Mean Absolute Percentage Error). Pehitungan nilai MAPE dilakukan dengan bantuan software MATLAB R2017a diperoleh nilai MAPE secara rinci ditampilkan pad Tabel 1.6. 
Tabel 1.6 Hasil Perhitungan Nilai MAPE

\begin{tabular}{|l|c|c|c|c|}
\hline \multirow{2}{*}{ Metode } & \multicolumn{4}{c|}{ Nilai MAPE $(\%)$} \\
\cline { 2 - 5 } & $K=32575$ & $K=33000$ & $K=33950$ & $K=34725$ \\
\hline Monte Carlo standar & 0,1 & 0,1 & 0,1 & 0,2 \\
\hline $\begin{array}{l}\text { Monte Carlo standar } \\
\text { Faure }\end{array}$ & 12,7 & 15,3 & 22,2 & 29,0 \\
\hline Monte Carlo bersyarat & 48,7 & 54,8 & 70,2 & 84,2 \\
\hline $\begin{array}{l}\text { Monte Carlo bersyarat } \\
\text { Faure }\end{array}$ & 0,7 & 3,2 & 2,1 & 0,7 \\
\hline
\end{tabular}

Sumber: Data diolah (2021)

Berdasarkan Tabel 1.6 diperoleh bahwa nilai MAPE dari metode Monte Carlo standar dan Monte Carlo bersyarat menggunakan barisan kuasi acak Faure adalah $<10 \%$, berdasarkan kriteria nilai MAPE maka nilai MAPE dikatakan sangat baik. Sedangkan untuk nilai MAPE dari metode Monte Carlo standar menggunakan barisan kuasi acak Faure berada pada rentang $10 \%-30 \%$, berdasarkan kriteria nilai MAPE maka diperoleh bahw a nilai MAPE masuk akal (wajar) sampai baik. Untuk nilai MAPE dari metode Monte Carlo Bersyarat berada pada rentang $40 \%-90 \%$, berdasarkan kriteria nilai MAPE sehingga nilai MAPE masuk akal (wajar) hingga tidak akurat. Hal ini berarti dengan melihat kriteria nilai MAPE, diperoleh bahwa metode Monte Carlo standar dan Monte Carlo bersyarat menggunakan barisan kuasi acak Faure dapat dikatakan lebih akurat dibandingkan Monte Carlo standar menggunakan barisan kuasi acak Faure, dan Monte Carlo bersyarat saat menghitung harga opsi beli tipe Eropa pada saham BBCA.JK.

\section{KESIMPULAN DAN SARAN}

\section{Kesimpulan}

Berdasarkan hasil pembahasan diperoleh bahwa harga opsi beli yang dihitung dengan metode Monte Carlo bersyarat menggunakan barisan kuasi acak Faure mulai stabil pada simulasi ke-5000 untuk $K=32575$ dengan harga opsi beli Rp 2.817,552 juga untuk $K=$ 34725 dengan harga opsi beli Rp 1.701,968, dan pada simulasi ke- 10000 untuk $K=33000$ dengan harga opsi beli Rp 2.294,716 serta untuk $K=33950$ dengan harga opsi beli Rp 1.830,342.

Dari hasil pembahasan juga diperoleh bahwa dengan metode Monte Carlo bersyarat menggunakan barisan kuasi acak Faure harga opsi beli tipe Eropa yang dihitung lebih cepat stabil dibandingkan metode Monte Carlo standar, Monte Carlo standar menggunakan barisan kuasi acak Faure, dan Monte Carlo bersyarat. Selain itu nilai MAPE yang diperoleh pada metode Monte Carlo bersyarat menggunakan barisan kuasi acak Faure dan metode Monte Carlo standar lebih kecil dari Monte Carlo standar menggunakan barisan kuasi acak Faure dan Monte Carlo bersyarat. Sehingga metode Monte Carlo bersyarat menggunakan barisan kuasi acak Faure dan metode Monte Carlo standar dapat dikatakan lebih akurat saat menghitung harga opsi beli tipe Eropa pada saham BBCA.JK.

\section{Saran}

Berdasarkan dari hasil yang diperoleh pada penelitian ini dengan metode Monte Carlo bersyarat menggunakan barisna kuasi acak Faure, penulis berharap bagi penelitian selanjutnya dapat:

1. Menentukan harga opsi tipe Amerika ataupun tipe yang lainnya dengan metode Monte Carlo bersyarat menggunakan barisan kuasi acak yang lain seperti Halton, Sobol dan Van der Corput, untuk mengetahui mana yang lebih cepat menuju nilai riilnya.

2. Mengestimasi volatilitas dengan menggunakan metode lain supaya dapat memberikan hasil yang lebih baik.

3. Menambahkan faktor-faktor lain yang dapat memengaruhi harga opsi seperti deviden supaya dapat memberikan hasil yang lebih baik.

\section{DAFTAR PUSTAKA}

Artanadi, N. N. A., Dharmawan, K. \& Jayanegara, K. (2017). Penentuan Harga Opsi Beli Tipe Asia Dengan Metode Monte Carlo-Control Variate. E-Jurnal Matematika, 6(1), 29-36.

Glasserman, P. (2004). Monte Carlo Methodsin Financial Engineering. New York: Springer. 
Granovsky, B. L. (1981). Optimal Formulae of the Conditional Monte Carlo. SIAM Journal on Algebraic Discrete Methods, 2(3), 289294.

Mahayoga, I. G. P. N., Dharmawan, K., \& Harini, L. P. I. (2014). Penentuan Harga Kontrak Opsi Tipe Eropa Menggunakan Metode Quasi Monte Carlo Dengan Barisan Kuasi-Acak Halton. E-Jurnal Matematika, 3(4), 154-159.

Ratnasari, D. A. A. P., Dharmawan, K., \& Nilakusmawati, D. P. E. (2017). Penentuan Nilai Kontrak Opsi Tipe Binary pada
Komoditas Kakao Menggunakan Metode Quasi Monte Carlo dengan Barisan Bilangan Acak Faure. E-Jurnal Matematika, 6(4), 214-219.

Wati, N. L. P. K., Dharmawan, K., \& Sari, K. (2018). Perbandingan Kekonvergenan Metode Conditional Monte Carlo dan Antithetic Variate dalam Menentukan Harga Opsi Call Tipe Barrier. E-Jurnal Matematika, 7(3), 271-277.

Zhang, H. (2009). Pricing Asian Options using Monte Carlo Methods. Swedia. 